\title{
Phenol hydroxylase cloned from Ralstonia eutropha strain E2 exhibits novel kinetic properties
}

\author{
Sanae Hino, ${ }^{1}$ Kazuya Watanabe ${ }^{1,2}$ and Nobuhiro Takahashi ${ }^{1}$ \\ Author for correspondence: Kazuya Watanabe. Tel: +81 19326 6537. Fax: +81 193266584. \\ e-mail: kazwata@kamaishi.mbio.co.jp
}

\footnotetext{
1 Corporate Research and Development Laboratories, Tonen Corporation, 1-3-1 Nishitsurugaoka, Ohi-machi, Iruma-gun, Saitama, Japan

2 Marine Biotechnology Institute, Kamaishi Laboratories, 3-75-1 Heita, Kamaishi City, Iwate, Japan
}

\begin{abstract}
Ralstonia eutropha strain E2 (previously Alcaligenes sp.) is a phenol-degrading bacterium expressing phenol-oxygenating activity with a low $K_{\mathrm{s}}$ (the apparent half-saturation constant in Haldane's equation) and an extremely high $K_{s 1}$ (the apparent inhibition constant). To identify the molecular basis for these novel cellular kinetic properties, a 9.5 kb DNA fragment that allowed Pseudomonas aeruginosa PAO1c ( $\mathrm{Phl}^{-} \mathrm{Cat}^{+}$) to grow on phenol as the sole carbon source was cloned from strain E2 into plasmid pRO1614. PAO1c harbouring this plasmid (designated pROE217) transformed phenol to catechol, indicating that this fragment contains gene(s) for phenol hydroxylase. The cloned genes consist of eight complete ORFs, designated poxRABCDEFG. The products are homologous to those of dmpRKLMNOPQ of Pseudomonas sp. CF600, sharing 30-65\% identity: this suggests that the phenol hydroxylase is a multicomponent enzyme. The kinetic constants for phenol-oxygenating activity of PAO1c(pROE217) were determined, and these were compared with those of strain E2. The kinetic constants of PA01c derivatives expressing different phenol hydroxylases were also determined. A comparison of these kinetic data suggests that phenol hydroxylase, the first enzyme in the phenol-degradative pathway, determines $K_{5}$ and $K_{51}$ values for the cellular phenol-oxygenating activity. It is thus suggested that the phenol hydroxylase cloned from strain E2 exhibits the novel kinetic properties that were observed with intact cells of strain E2.
\end{abstract}

Keywords: phenol-oxygenating activity, phenol hydroxylase, kinetics, Ralstonia eutropha

\section{INTRODUCTION}

Phenolic compounds are known to be potential environmental pollutants discharged from industrial plants. Biodegradation of phenolics by bacteria has thus been a central subject in environmental microbiology, and a large number of phenol-degrading bacteria have been isolated. In our previous study, phenol-degrading bacteria were isolated from oil-refinery activated sludge, and the kinetics for phenol-oxygenating activities of these isolates and those of several known phenoldegrading bacteria were investigated in intact cells (Watanabe et al., 1996). It was found that the phenoldegrading bacteria tested can be classified into several kinetically different groups according to $K_{\mathrm{s}}$ (the ap-

The GenBank/EMBLDDBJ accession number for the $9.5 \mathrm{~kb}$ sequence reported in this paper is AF026065. parent half-saturation constant in Haldane's equation) and $K_{\mathrm{SI}}$ (the apparent inhibition constant) values. However, Ralstonia eutropha strain E2 (previously Alcaligenes sp.), one of our isolates, did not belong to any group, exhibiting novel kinetic properties, i.e. a low $K_{\mathrm{s}}$ value and an extremely high $K_{\mathrm{SI}}$ value (Watanabe $e t$ al., 1996). These kinetic constants of strain E2 were also different from those previously reported by other researchers (Folsom et al., 1990; Hashimoto et al., 1992). We were thus interested in identifying the molecular basis for the novel kinetics for the cellular phenoloxygenating activity of strain E2 with an expectation that a novel phenol-degradative enzyme might exist.

Although there have been many reports documenting the kinetic evaluation of phenol-degrading bacteria (Folsom et al., 1990; Hashimoto et al., 1992; Watanabe et al., 1996) and also describing identification of bacterial phenol-degradative enzymes (Nordlund et al., 1990; 
Kukor \& Olsen, 1990; Nurk et al., 1991; Ng et al., 1994; Herrmann et al., 1995; Ehrt et al., 1995; Takeo et al., 1995), it has not yet been identified which molecules in the cell determine the cellular kinetic properties for phenol degradation. Among several possibilities, such as phenol-uptake systems and enzymes in the degradative pathways, phenol hydroxylase, the first enzyme in the bacterial phenol-degradative pathway, was assumed to be most likely to determine the $K_{\mathrm{s}}$ and $K_{\mathrm{SI}}$ values for phenol degradation by bacteria. In this study, to verify this assumption, genes for phenol hydroxylase of strain E2 were cloned, and the kinetics for phenol-oxygenating activity of Pseudomonas aeruginosa $\mathrm{PAO} 1 \mathrm{c}\left(\mathrm{Phl}^{-} \mathrm{Cat}^{+}\right)$ expressing the phenol hydroxylase of strain E2 were examined. In addition, the genes were sequenced to compare the putative amino acid sequences with those of the products of previously sequenced phenol hydroxylase genes.

\section{METHODS}

Bacterial strains and plasmids. The bacterial strains and plasmids used in this study are listed in Table 1. Ralstonia eutropha strain E2 (previously Alcaligenes sp.) had been isolated from phenol-acclimatized oil-refinery activated sludge by using agar plates containing dCGY medium after enrichment in a continuous culture fed on phenol as the sole carbon source (Watanabe et al., 1996). Strain E2 was affiliated with $R$. eutropha according to the nucleotide sequence of the 16S rRNA gene (accession number AB007998). Strain E2 was capable of growing on phenol as the sole carbon source, phenol being mineralized by strain $\mathrm{E} 2$ through a meta-cleavage pathway (Watanabe et al., 1996). P. aeruginosa PAO1c is capable of growing on catechol, but not on phenol (Holloway et al., 1979).

Media and growth conditions. The culture media used in this study were LB medium (Sambrook et al., 1989), dLB medium $\left(1^{-1}: 0.5 \mathrm{~g}\right.$ Bacto yeast extract, $1 \mathrm{~g}$ Bacto tryptone and $1 \mathrm{~g}$ $\mathrm{NaCl}$ ) and an inorganic medium called MP (Watanabe et al., 1996). The strains of P. aeruginosa and Escherichia coli were grown at $37^{\circ} \mathrm{C}$, while strain E2 was grown at $30^{\circ} \mathrm{C}$. Tetracycline, ampicillin, kanamycin and carbenicillin were used in selective media at concentrations of 50,50,50 and $500 \mu \mathrm{g} \mathrm{ml}^{-1}$, respectively.

Genetic techniques. Plasmid isolation from the E. coli strains, restriction endonuclease digestion and transformation of the $E$. coli strains were conducted as described by Sambrook $e t$ al. (1989). The $P$. aeruginosa strains were transformed as described by Chakrabarty et al. (1975).

Table 1. Bacterial strains and plasmids

\begin{tabular}{|c|c|c|}
\hline Strain/plasmid & Relevant markers and derivation* & Reference/source \\
\hline \multicolumn{3}{|l|}{ Strain } \\
\hline R. eutropha E2 & $\mathrm{Phl}^{+}$ & Watanabe et al. (1996) \\
\hline P. aeruginosa $\mathrm{PAO} 1 \mathrm{c}$ & $\mathrm{Phl}^{-} \mathrm{Cat}^{+}$ & Holloway et al. (1979) \\
\hline E. coli VCS257 & Host strain of cosmid vector, supF derivative of DP50 & Stratagene \\
\hline E. coli JM109 & 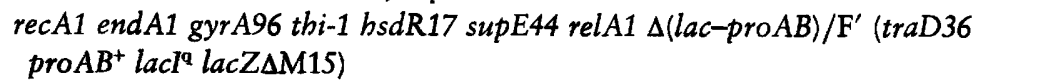 & Sambrook et al. (1989) \\
\hline \multicolumn{3}{|c|}{ 然 } \\
\hline pLAFR3 & Cosmid vector derived from pLAFR1, IncP1, $\lambda \cos ^{+} r l x, \mathrm{Tc}^{\mathrm{r}}$ & Staskawicz et al. (1987) \\
\hline pUC18 & $\mathrm{Ap}^{\mathrm{r}} / \mathrm{Cb}^{\mathrm{r}}$, cloning vector & Sambrook et al. (1989) \\
\hline pUC118 & $\mathrm{Ap}^{\mathrm{r}} / \mathrm{Cb}^{\mathrm{r}}$, cloning vector & Sambrook et al. (1989) \\
\hline pRO1614 & $\mathrm{Ap}^{r} / \mathrm{Cb}^{r} \mathrm{Tc}^{\mathrm{r}}$, cloning vector & Olsen et al. (1982) \\
\hline pRO1959 & $\mathrm{Ap}^{\mathrm{r}} / \mathrm{Cb}^{\mathrm{r}} \mathrm{Ph} l^{+}$, containing cloned $p h l A$ and $p h l R$ of $B$. pickettii $\mathrm{PKO} 1$ & Kukor et al. (1990) \\
\hline pS04-92 & $\mathrm{Km}^{\mathrm{r}} \mathrm{Ph} \mathrm{l}^{+}$, containing cloned pheA and phe $\mathrm{R}$ of $P$. putida $\mathrm{BH}$ & Fujita et al. (1995) \\
\hline pROBH01 & $\begin{array}{l}\mathrm{Ap}^{\mathrm{r}} / \mathrm{Cb}^{\mathrm{r}}, 6.8 \mathrm{~kb} \text { Nrul fragment of pS04-92 cloned into the EcoRV site of } \\
\text { pRO1614 }\end{array}$ & This study \\
\hline pRO1614M & $\begin{array}{l}\mathrm{Ap}^{\mathrm{r}} / \mathrm{Cb}^{\mathrm{r}}, \text { multicloning site of pUC18 inserted into EcoRI-HindIII-cleaved } \\
\text { pRO1614 }\end{array}$ & This study \\
\hline pLAFRE201 & $\begin{array}{l}\mathrm{Ap} \mathrm{p}^{\mathrm{r}} / \mathrm{Cb}^{\mathrm{r}}, 23 \mathrm{~kb} \text { Sau3AI partially digested DNA fragment from Ralstonia sp. E2 } \\
\text { cloned into pLAFR3 }\end{array}$ & This study \\
\hline pLAFRE202 & $\mathrm{Tc}^{\mathrm{r}}, 16 \mathrm{~kb}$ EcoRI fragment deleted from pLAFRE201 & This study \\
\hline pUCE203 & $\mathrm{Ap}^{\mathrm{r}} / \mathrm{Cb}^{\mathrm{r}}, 11.5 \mathrm{~kb}$ BamHI fragment of pLAFRE201 cloned into pUC18 & This study \\
\hline pROE204 & $\mathrm{Ap}^{\mathrm{r}} / \mathrm{Cb}^{\mathrm{r}}, 12.5 \mathrm{~kb}$ NheI-KpnI fragment of pLAFRE201 cloned into $\mathrm{pRO} 1614 \mathrm{M}$ & This study \\
\hline pROE206 & $\mathrm{Ap}^{\mathrm{r}} / \mathrm{Cb}^{\mathrm{r}}, 6.6 \mathrm{~kb}$ EcoRI fragment of pLAFRE201 cloned into pRO1614 & This study \\
\hline pUCE207 & $\mathrm{Ap}^{\mathrm{r}} / \mathrm{Cb}^{\mathrm{r}}, 3.5 \mathrm{~kb} \mathrm{KpnI}-\mathrm{E} c \mathrm{RI}$ fragment of pLAFRE201 cloned into pUC118 & This study \\
\hline pROE216 & $\begin{array}{l}\mathrm{Ap}^{\mathrm{r}} / \mathrm{Cb}^{\mathrm{r}}, 10 \cdot 5 \mathrm{~kb} \text { EcoRI partially digested fragment of pLAFRE201 cloned into } \\
\mathrm{pRO} 1614\end{array}$ & This study \\
\hline pROE217 & $\mathrm{Ap}^{\mathrm{r}} / \mathrm{Cb}^{\mathrm{r}}, 10 \mathrm{~kb}$ ClaI-Nhel fragment of pLAFRE201 cloned into pRO1614 & This study \\
\hline pROE218 & $\begin{array}{l}\mathrm{Ap}^{\mathrm{r}} / \mathrm{Cb}^{\mathrm{r}}, 10 \mathrm{~kb} E c o \mathrm{RI} \text { partially digested fragment of pLAFRE } 201 \text { cloned into } \\
\mathrm{pRO} 614\end{array}$ & This study \\
\hline
\end{tabular}

" Phl, growth on phenol; Cat, growth on catechol. 
Cloning and screening strategies. Total DNA of strain E2 was extracted by the procedure of Marmur (1961). A cosmid library was prepared by ligating partially Sau3AI-digested total DNA into broad-host-range cosmid vector pLAFR3 (Staskawicz et al., 1987). After in vitro packaging into bacteriophage $\lambda$, using a Gigapack II in vitro packaging kit (Stratagene), E. coli VCS257 was transfected with the phage. Approximately 2500 recombinant $E$. coli clones were tested for the formation of the yellow meta-cleavage product of catechol by spraying with $5 \%(\mathrm{w} / \mathrm{v})$ catechol (these clones grew on agar plates containing the $\mathrm{dLB}$ medium supplemented with $10 \mathrm{mM} \mathrm{MgSO}, 0.2 \%$ maltose, $250 \mathrm{mg}$ phenol $\mathrm{l}^{-1}$ and tetracycline). The catechol meta-cleavage activity of E. coli JM109 harbouring subfragments was assayed on dLB plates supplemented with phenol $\left(250 \mathrm{mg} \mathrm{l}^{-1}\right)$ and ampicillin.

Phenol utilization by recombinant $\boldsymbol{P}$. aeruginosa strains. DNA fragments of a recombinant pLAFR3 plasmid were subcloned into $\mathrm{pRO} 1614$ or $\mathrm{pRO} 1614 \mathrm{M}$, and $P$. aeruginosa $\mathrm{PAO} 1 \mathrm{c}$ was transformed with the resultant plasmids. Colonies on LB plates supplemented with carbenicillin were directly inoculated into $5 \mathrm{ml}$ MP medium supplemented with carbenicillin and phenol $\left(250 \mathrm{mg} \mathrm{l}^{-1}\right)$. Growth was monitored by measuring the $\mathrm{OD}_{660}$ of the culture (Beckman model DU 640 spectrophotometer). The phenol concentration was measured by using the Phenol Test Wako kit (Wako Pure Chemical) as described previously (Watanabe \& Hino, 1996). Catechol in the culture media was detected by HPLC with an 8010 HPLC system (Tosoh) equipped with a UV-8010 detector (Tosoh) and a reverse-phase column (Inertsil ODS-80A, $5 \mu \mathrm{m}$, $4.6 \times 150 \mathrm{~mm}$; GL Science). Cells were removed from each culture by filtering through a $0.22 \mu \mathrm{m}$ pore-size membrane, and $100 \mu \mathrm{l}$ of the filtrate was injected for HPLC. The mobile phase was acetic acid/water $(1: 99, \mathrm{v} / \mathrm{v})$ at a flow rate of $1 \mathrm{ml}$ $\mathrm{min}^{-1}$, and the eluate was monitored at $260 \mathrm{~nm}$. Catechol in the medium was identified by comparing its retention time with that of the pure reagent of catechol (Wako Pure Chemical).

Nucleotide sequencing and computer analysis. To determine the nucleotide sequence of the $9.5 \mathrm{~kb}$ DNA fragment, subfragments were cloned into the multicloning site of pUC18. Nucleotide sequencing of the subfragments in both orientations was carried out by using the M13 primers, a DNA sequencing kit (Dye Terminator Cycle Sequencing; Perkin Elmer) and a 370A DNA sequencer (Applied Biosystems) according to the manufacturers' instructions. The DNA sequence data and deduced amino acid sequences were analysed using version $2.0 \mathrm{x}$ of the FASTA program package (Pearson \& Lipman, 1988; Pearson, 1990) and version 1.7 of CLUSTAL w (Thompson et al., 1994).

Kinetic analysis of phenol-oxygenating activity. The cells used for measuring phenol-oxygenating activity were freshly sampled from a continuous culture immediately before the activity measurement: a TBR-2 fermenter (Sakura Fine Technical) with a capacity of 21 was used. The culture at $37^{\circ} \mathrm{C}$ with the working volume of 11 was started by inoculating cells grown in $30 \mathrm{ml} \mathrm{LB}$ medium supplemented with carbenicillin and then washing with the MP medium. The MP medium, supplemented with phenol $\left(1000 \mathrm{mg} \mathrm{l}^{-1}\right)$, Casamino acids $\left(3000 \mathrm{mg} \mathrm{l}^{-1}\right)$ and carbenicillin, was continuously supplied at a flow rate of $0.21 \mathrm{~d}^{-1}$, and air was supplied at $1.51 \mathrm{~min}^{-1}$. The cells were sampled after the culture parameters $(\mathrm{pH}$, dissolved oxygen concentration, phenol concentration and $\mathrm{OD}_{660}$ ) had become stable, i.e. at least $3 \mathrm{~d}$ after commencing the culture. The dry cell weight in the culture was determined gravimetrically by filtering through a $0.22 \mu \mathrm{m}$ pore-size membrane according to the method of Machado \& Grady (1989). The phenol-oxygenating activity was measured with a Clark-type oxygen electrode $(5 / 6$ Oxygraph; Gilson) as described previously (Watanabe $e t$ al., 1996). One unit of activity is defined as the amount of material required to catalyse the consumption of $1 \mu \mathrm{mol}$ oxygen $\mathrm{min}^{-1}$, while the specific activity is defined as the activity ( $\mathrm{g}$ dry wt cells) $^{-1}$. The apparent kinetic constants $K_{\mathrm{s}}, K_{\mathrm{sI}}$ and $V_{\max }$ in Haldane's equation (Watanabe et al., 1996) were determined by a non-linear regression method as described previously (Watanabe et al., 1996).

\section{RESULTS}

\section{Cloning and mapping}

One clone which showed a yellowish colour on the plate containing phenol was obtained and designated VCS257(pLAFRE201); the yellowish colour was deepened by the catechol spray. It is thus considered that this $E$. coli clone transformed phenol to 2-hydroxymuconic semialdehyde via catechol. Mapping of the restriction endonuclease sites (Fig. 1) indicated the size of the insertion fragment in pLAFRE201 to be approximately $23 \mathrm{~kb}$. Subclones were constructed, and the abilities of the subclones to allow PAO1c to grow on phenol as the sole carbon source and to allow JM109 to produce the yellow meta-cleavage product from catechol were tested (Fig. 1). As shown in the figure, pROE217 allowed PAO1c to grow on phenol, and pUCE206, pUCE207 and pUCE216 allowed JM109 to produce the yellow product from catechol. These results suggest that the genes for phenol hydroxylase and catechol 2,3-dioxygenase were located in DNA fragments E217 $(9.5 \mathrm{~kb})$ and E207 $(4.5 \mathrm{~kb})$, respectively.

When PAO1c(pROE217) was grown on a dLB plate containing $250 \mathrm{mg}$ phenol $\mathrm{1}^{-1}$ and carbenicillin, brownish colonies appeared, suggesting that catechol had been produced from phenol. In addition, when PAO1c(pROE217) was grown in the MP medium supplemented with phenol as the sole carbon source, catechol was detected by the HPLC analysis of the fluid of an exponentially growing culture (data not shown), indicating that E217 contains the gene(s) for phenol hydroxylase of strain E2.

\section{Sequence analysis}

The nucleotide sequence of the $9.5 \mathrm{~kb}$ fragment (E217) was determined. Eight complete ORFs preceded by putative Shine-Dalgarno sequences (Shine \& Dalgarno, 1975) were identified in the sequence; these ORFs were designated poxR and poxABCDEFG. All these ORFs are considered to be transcribed in the same orientation. A possible regulatory region for poxABCDEFG is presented in Fig. 2. A putative promoter sequence similar to that of the $\sigma^{54}(\mathrm{RpoN})$-dependent $-24 /-12$ type of promoter (Dixon, 1986) was located immediately upstream of poxA. The seven ORFs (poxA-G) are possibly transcribed from this promoter. A long inverted repeat centred at approximately $130 \mathrm{bp}$ upstream of the puta- 


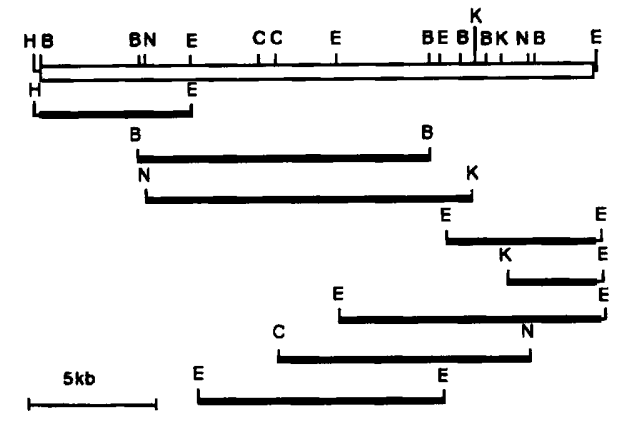

\begin{tabular}{ccc}
\hline \multirow{2}{*}{$\begin{array}{c}\text { DNA } \\
\text { fragment }\end{array}$} & \multicolumn{2}{c}{ Activity } \\
\cline { 2 - 4 } & Phe & C230 \\
\hline E201 & ND & + \\
E202 & - & - \\
E203 & ND & - \\
E204 & - & - \\
E206 & - & + \\
E207 & ND & + \\
E216 & - & + \\
E217 & + & - \\
E218 & - & - \\
\hline
\end{tabular}

Fig. 1. Restriction endonuclease map of the $23 \mathrm{~kb}$ DNA fragment from strain E2, and subclones derived therefrom. Details of plasmid construction are provided in Table 1. Phe indicates the ability to allow PAO1c to grow on phenol as the sole carbon source, and $\mathrm{C} 230$ indicates the ability to allow $E$. coli strains to produce the yellow pigment from catechol. +, Positive; negative; ND, not determined; H, Hind III; $B$, BamHI; N, Nhel; E, ECoRI; C, Clal; K, KpnI.

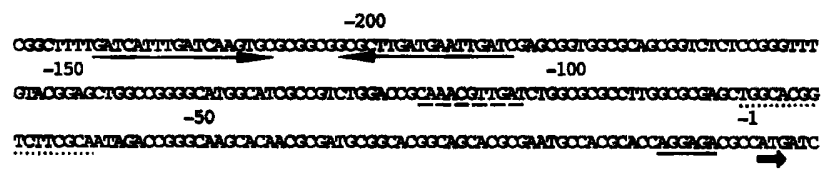

Fig. 2. Nucleotide sequence of a putative regulatory region for the poxABCDEFG genes. A bold short arrow indicates the initiation codon for PoxA. A possible ribosome-binding site is indicated with a solid underline. Dotted and dashed underlines indicate a putative promoter region and an IHF-binding region, respectively. Long arrows in both directions indicate a long inverted repeat which is a possible positive-regulator-binding site.

tive promoter was found. Inverted repeats have also been found in regulatory regions at corresponding positions of the Pseudomonas TOL upper pathway operon (Abril et al., 1991), the xylS gene (Holtel et al., 1992) and the $d m p$ operon (Shingler et al., 1993). A sequence homologous to the consensus IHF recognition sequence (Friedman, 1988) was found between the putative promoter sequence and the long inverted repeat. These findings, coupled with the existence of poxR (see below), imply that the expression of Pox$A B C D E F G$ proteins would be controlled by a positive regulatory mechanism that is similar to ones already known. It was found that pox (initiation codon is approximately $2500 \mathrm{bp}$ upstream of that for $p o x A$ ) was also preceded by a typical sequence for the $\sigma^{54}(\mathrm{RpoN})$ - dependent $-24 /-12$ type promoter, i.e. TGGC-N8TGCA, that is located approximately $60 \mathrm{bp}$ upstream of the initiation codon for poxR.

Database searches, using the deduced amino acid sequences of PoxR, A, B, C, D, E, F and G, revealed homology with those of previously sequenced multicomponent phenol hydroxylases. Table 2 summarizes the identity and similarity of each pox product with those of the dmp operon in Pseudomonas sp. CF600 (Nordlund et al., 1990) and the mop operon in Acinetobacter calcoaceticus NCIB 8250 (Ehrt et al., 1995). The $d m p$ and mop phenol hydroxylases are homologous to each other with respect to molecular structure and amino acid sequence, sharing $45-72 \%$ identity. In addition to these two strains, the genes for multicomponent phenol hydroxylases have also been cloned and sequenced from several phenol-degrading bacteria, including Pseudomonas putida P35X (Ng et al., 1994), P. putida strain H (Herrmann et al., 1995) and P. putida BH (Takeo et al., 1995); these gene products are highly homologous to the dmp products, sharing $86-100 \%$ identity. PoxR is homologous to DmpR (Shingler et al., 1993), suggesting that PoxR belongs to the NtrC family of transcriptional activators (Kustu et al., 1989). When bound to an effector molecule such as phenol, PoxR may positively regulate the expression of PoxA to PoxG through binding to the upstream inverted repeat sequence. Proteins PoxA to PoxF are considered to be components of the phenol hydroxylase, while PoxG

Table 2. Summary of the pox products and comparison with isofunctional proteins

\begin{tabular}{|lrll|}
\hline Product & $\begin{array}{c}\text { No. of } \\
\text { residues }\end{array}$ & Possible function & \multicolumn{1}{c|}{ Identity/similarity (\%) } \\
\hline PoxR & 568 & Regulator & DmpR (50/77), MopR (46/74) \\
PoxA & 74 & Phenol hydroxylase & DmpK (30/49), MopK (33/47) \\
PoxB & 331 & Phenol hydroxylase & DmpL (52/75), MopL (47/76) \\
PoxC & 90 & Phenol hydroxylase & DmpM (50/81), MopM (49/87) \\
PoxD & 504 & Phenol hydroxylase & DmpN (65/86), MopN (66/85) \\
PoxE & 119 & Phenol hydroxylase & DmpO (45/69), MopO (38/63) \\
PoxF & 356 & Phenol hydroxylase & DmpP (60/77), MopP (53/77) \\
PoxG & 101 & Ferredoxin-like protein & DmpQ (40/61) \\
\hline
\end{tabular}




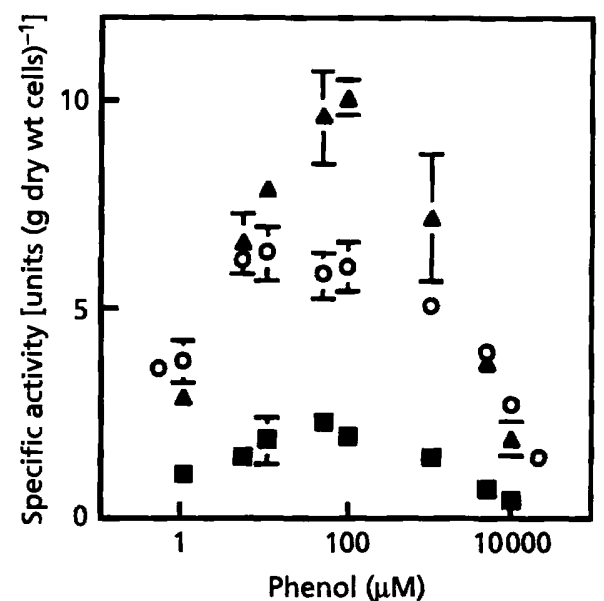

Fig. 3. Phenol-oxygenating activities of PAO1c(pROE217) (O), PAO1c(pRO1959) (G) and PAO1c(pROBH01) (A). Each datum point and bar represent the mean and standard error of three determinations, respectively.

(homologous to DmpQ) may be a ferredoxin-like protein having a similar function to XylT, i.e. the reactivation of catechol 2,3-dioxygenase (Polissi \& Harayama, 1993). The results of the homology analysis suggest that the phenol hydroxylase of strain E2 belongs to the multicomponent enzyme group.

\section{Kinetics for the phenol-oxygenating activity of PAO1c(PROE217)}

The phenol-oxygenating activity of PAO1c(pROE217) was measured, and the data were compared with those of PAO1c(pRO1959) and PAO1c(pROBH01). The pRO1959 plasmid contains $p h l A$ and $p h l R$ of Burkholderia pickettii PKO1 and allowed PAO1c to grow on phenol as the sole carbon source (Kukor \& Olsen, 1990), the phlA gene encoding a single-component phenol hydroxylase (Kukor \& Olsen, 1990). The pROBH01 plasmid contains pheR and pheA123456 of strain $\mathrm{BH}$ and allowed PAO1c to grow on phenol as the sole carbon source. The multicomponent enzyme of $\mathrm{BH}$ is highly homologous to that of $P$. putida CF600 (the $d m p$ products), there being only one amino acid substitution in PheA6 (Takeo et al., 1995). In addition, strains BH and CF600 expressed almost identical kinetics for the phenol-oxygenating activity (Watanabe et al., 1996). These three recombinant derivatives of PAO1c showed phenol-dependent oxygen consumption, although PAO1c itself did not. The phenol-oxygenating activities of the three recombinant strains were measured at phenol concentrations from $0.5 \mu \mathrm{M}$ to $20 \mathrm{mM}$ and are plotted against phenol concentrations (Fig. 3). By using the data in Fig. 3, the apparent kinetic constants for the phenol-oxygenating activities of PAO1c(pROE217), PAO1c(pRO1959) and PAO1c(pROBH01) were determined (Table 3): these values were then compared with each other and with those of strains E2, PKO1 and BH previously reported (Watanabe et al., 1996). This table shows that the three recombinant derivatives of PAO1c exhibited different $K_{\mathrm{s}}$ and $K_{\mathrm{SI}}$ values. It is also shown that the $K_{\mathrm{s}}$ and $K_{\mathrm{SI}}$ values of PAO1c(pROE217), PAO1c(pRO1959) and PAO1c(pROBH01) are almost identical to those of strains E2, PKO1 and $\mathrm{BH}$, respectively. The $V_{\max }$ values of the recombinant strains were low compared with those of the authentic phenol degraders, while the degree of reduction in the $V_{\max }$ value of the $\mathrm{BH}$ phenol hydroxylase was much less than those of the other phenol hydroxylases. This may have been due to the different phylogenetic distances between PAO1c and the authentic hosts of the phenol hydroxylases.

\section{DISCUSSION}

A comparison of the kinetic data suggests that, regardless of the enzyme structures, phenol hydroxylases, the first catabolic enzymes in bacterial phenol-degradative pathways, determine $K_{\mathrm{s}}$ and $K_{\mathrm{SI}}$ values for phenoloxygenating activity expressed by bacterial cells. Thus it is suggested that the phenol hydroxylase cloned from strain E2 exhibits the novel kinetic properties, i.e. the low $K_{\mathrm{s}}$ and the extremely high $K_{\mathrm{SI}}$ values, that had been observed with intact cells of E2 (Watanabe et al., 1996).

Table 3. Apparent kinetic constants in Haldane's equation for specific phenoloxygenating activities of PAO1c(pROE217), PAO1c(pRO1959) and PAO1c(PROBH01)

Data are estimated values \pm SE.

\begin{tabular}{|lllc|}
\hline & $K_{\mathbf{s}}(\boldsymbol{\mu M})$ & $K_{\mathrm{sl}}(\boldsymbol{\mu M})$ & $\begin{array}{c}\boldsymbol{V}_{\max } \\
\text { [units (g dry wt cells) }\end{array}$ \\
\hline PAO1c(pROE217) & & $7700 \pm 1400$ & $6 \cdot 2 \pm 0 \cdot 2$ \\
PAO1c(pRO1959) & $0 \cdot 47 \pm 0 \cdot 11$ & $2200 \pm 500$ & $2 \cdot 2 \pm 0 \cdot 1$ \\
PAO1c(pROBH01) & $1 \cdot 80 \pm 0 \cdot 50$ & $2600 \pm 400$ & $11 \cdot 0 \pm 0 \cdot 3$ \\
E2 $^{*}$ & $3 \cdot 65 \pm 0 \cdot 42$ & $7360 \pm 500$ & $155 \cdot 0 \pm 7 \cdot 0$ \\
PKO1 $^{*}$ & $0 \cdot 36 \pm 0.06$ & $1700 \pm 370$ & $57 \cdot 0 \pm 3 \cdot 0$ \\
BH $^{*}$ & $1 \cdot 49 \pm 0 \cdot 42$ & $2820 \pm 760$ & $40 \cdot 0 \pm 3 \cdot 0$ \\
\hline
\end{tabular}

* Data are cited from a reference (Watanabe et al., 1996). 
P1

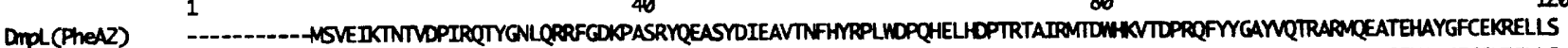
PhinL

Phin

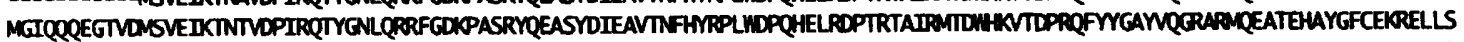

PoxB

Mopl

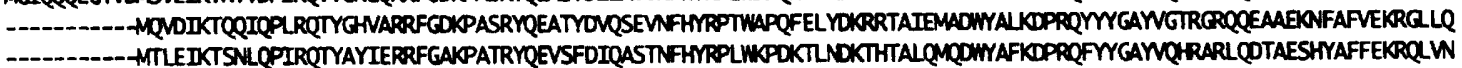

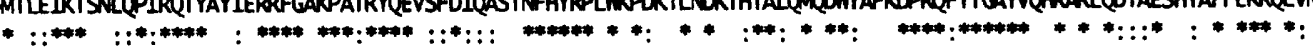

12 160 200

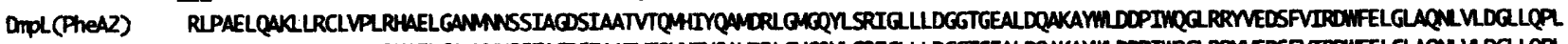

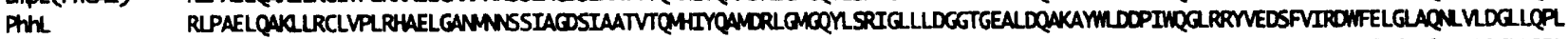

POXB

Mopl

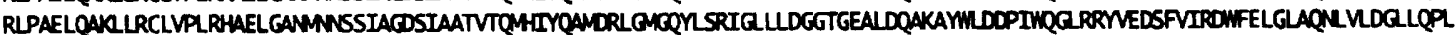

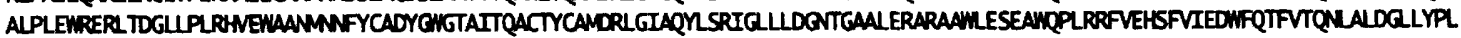

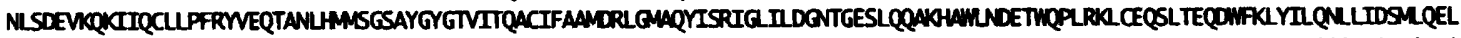

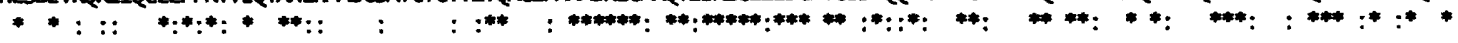
241280

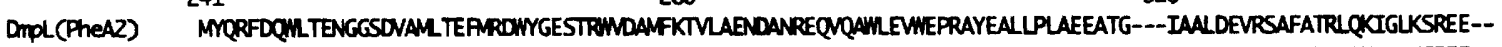

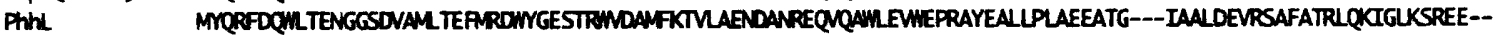

PhlB

POXB MMQPFDQMLTENGGSOVAM TEAROMYGESTRWOAFKTMLAENDANREQVAMLWWEPRAYEALLPLAEEATG---IALLDEVRSAFATRLQKTGLKSPEE-WOHADAATMRACGTGAWTEANDWPOEHMRWDAWOTAAAESEANRALLSRMAGEARAQAAEALPPVAATL LGEGEOATALCLEQFDARLAKLGVAA-----

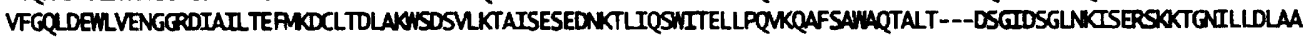
$:::^{*}::^{*}::^{* * *}::^{* *}:::^{*}::^{*}:::^{*}::^{*}: *:^{*} * *$

P3 1 40

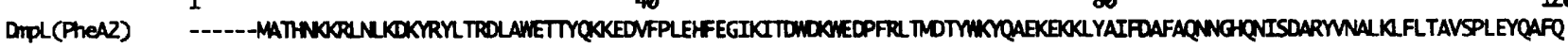
PThN

Phlo

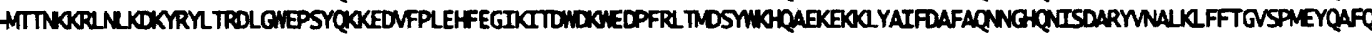

MopN

POXD

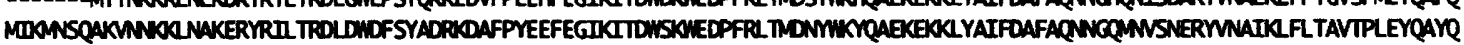

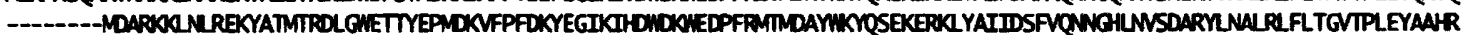

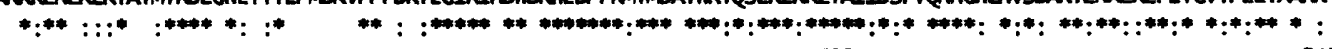

121

160

200

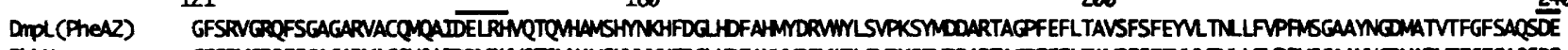

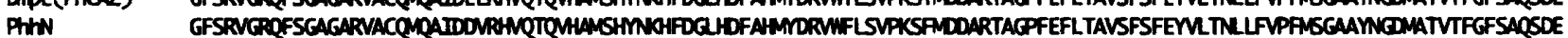

Thio

MopN

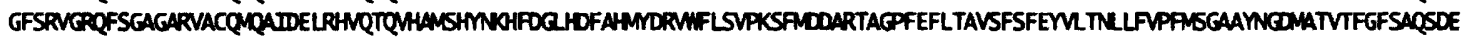

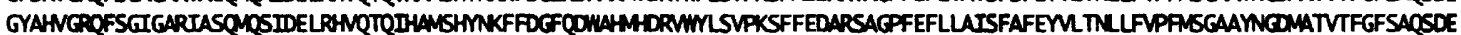

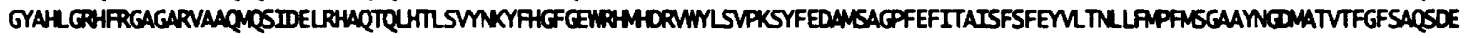

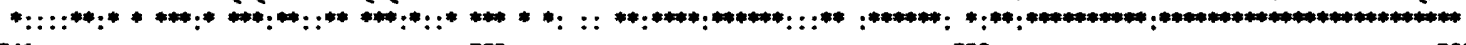
241 280 320

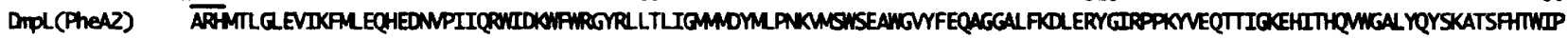

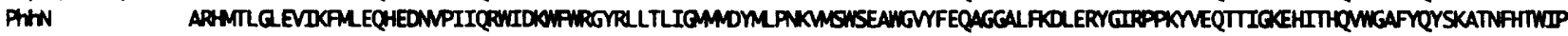

PhlD

MopN

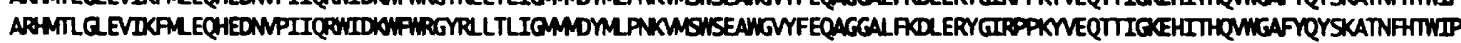

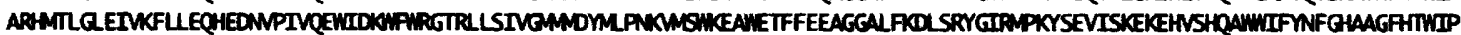

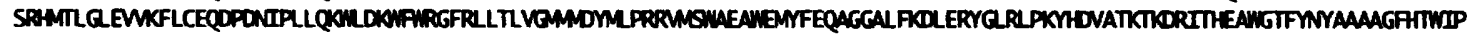

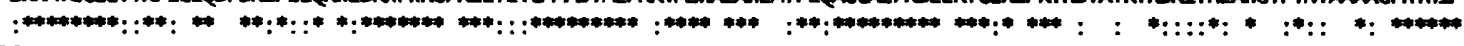
361

$$
400
$$

440

480

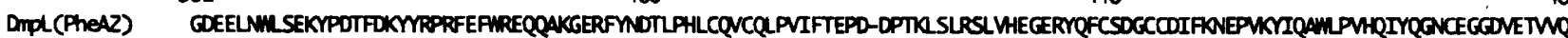

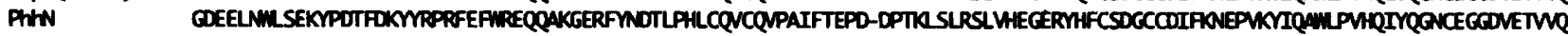

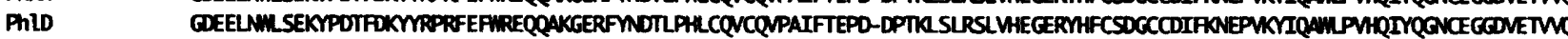

MopN POXD

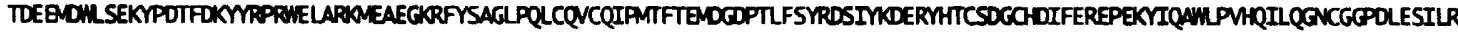

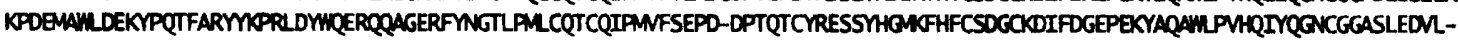
481

$$
: *: * * * *: * *: * *: * *:::: *: * * * * 0
$$

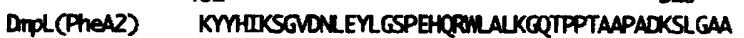

PhIN KMIIKSOVDKENGSPEHQPMLALKCQTPPTAAPADKSLDAA

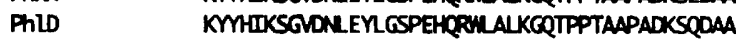

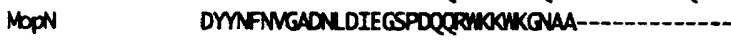

PoxD KOMRLNLGAONUDFEGSCOOMWNAMKGMPAPAA-

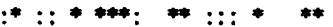

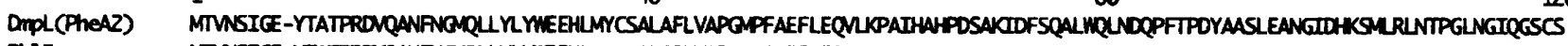

PhlE

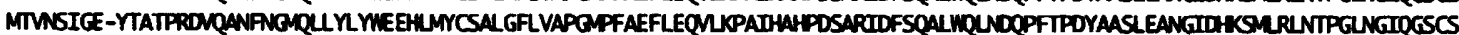

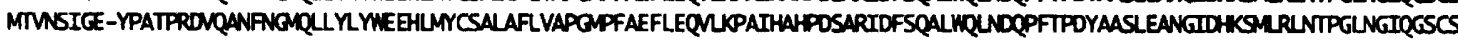

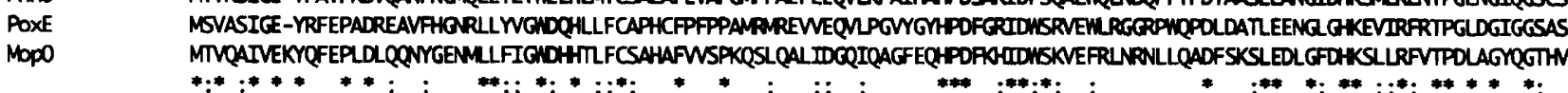

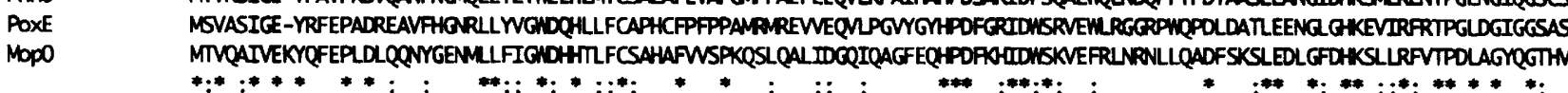

Fig. 4. Alignment of the deduced amino acid sequences of hydroxylase components in multicomponent phenol hydroxylases. Identical and similar amino acids among all aligned sequences are indicated with asterisks and colons below the sequences, respectively. Solid lines above the sequences indicate two DE(D)XRH motifs. Sequences: Dmp, Pseudomonas sp. CF600 (Nordlund et al., 1990); Phe, P. putida BH (Takeo et al., 1995); Phl, P. putida H (Herrmann et al., 1995); Phh, P. putida P35X (Ng et al., 1994); Mop, A. calcoaceticus NClB 8250 (Ehrt et al., 1995); Pox, R. eutropha E2 (this study). 
As has been reported for other phenol-degrading bacteria (Powlowski \& Shingler, 1990), the purification of multicomponent phenol hydroxylases is recognized to be very difficult. In the case of strain E2, the phenoloxygenating activity became undetectable immediately after disrupting the cells, even in the presence of cofactors, i.e. $\mathrm{Fe}^{2+}$ and $\mathrm{NAD}(\mathrm{P}) \mathrm{H}$ (unpublished data). This may be the major reason why the kinetic properties of bacterial phenol hydroxylases have not been well understood. This study demonstrated that an in vivo system with PAO1c is very useful for determining the $K_{\mathrm{s}}$ and $K_{\mathrm{SI}}$ values of labile phenol hydroxylases.

Our previous study showed that the oil-refinery activated sludge from which strain E2 had been isolated exhibited E2-type kinetics for phenol-oxygenating activity when it was fed on phenol as the sole carbon source (Watanabe \& Hino, 1996). This fact, coupled with the results of the present study, suggests that the phenol hydroxylase cloned from strain E2 (Pox) was functionally dominant in the activated-sludge microbial community. Although it has not yet been elucidated why the Pox-type phenol hydroxylase played the dominant role in the activated sludge, it would be interesting to investigate the distribution of the Pox-type phenol hydroxylase in other microbial communities. The nucleotide sequence determined in this study will be useful to design specific probes for detecting the $p o x$ genotype in the environment.

The fact that phenol hydroxylase determines the kinetic constants for cellular phenol-oxygenating activity implies that the engineering of phenol hydroxylase would allow bacterial activity for phenol degradation to be improved. We have reported that bacterial phenoloxygenating activity could be classified into several groups according to the $K_{\mathrm{s}}$ and $K_{\mathrm{SI}}$ values (Watanabe $e t$ al., 1996), implying that several kinetically different groups of phenol hydroxylases exist in nature. Cloning and sequence analysis of these phenol hydroxylases will provide useful information for engineering phenol hydroxylases and thus for constructing the desired phenol-degrading bacteria.

The results of the nucleotide sequence analysis suggest that the pox product is a multicomponent enzyme that is structurally analogous to the well-characterized $d m p$ products (Shingler, 1996), although the deduced amino acid sequences of the pox products were unexpectedly different from those of the $d m p$ products. The known multicomponent phenol hydroxylases are classified into two types according to the genetic organization of the operons, i.e. (i) the $d m p$ type followed by genes for a ferredoxin-like protein and a catechol 2,3-dioxygenase (Shingler, 1996), and (ii) the mop type followed by a gene for catechol 1,2-dioxygenase without a gene for a ferredoxin-like protein (Ehrt et al., 1995). Based on this criterion, pox belongs to the $d m p$ type, although it is the only known example of the gene which is not highly homologous to equivalent genes of the other members of the $d m p$ group.

Genetic and biochemical analyses of the phenol hy- droxylase of CF600 indicate that six polypeptides are required for growth on a phenolic substrate, while five polypeptides (not $\mathrm{DmpK}$ ) were indispensable for phenol hydroxylase activity in vitro (Powlowski \& Shingler, 1990). Among these six polypeptides, DmpLNO have been suggested to be components of hydroxylase (Shingler, 1996). Hence, the deduced amino acid sequences of the P1, P3 and P4 components (corresponding to DmpLNO, respectively) of the known phenol hydroxylases were compared to identify the conserved regions (Fig. 4). Among the three components, P3, the largest, was found to be most conserved; $55 \%$ of the amino acids were identical among all the phenol hydroxylases. In particular, the middle part of this component (from amino acids 126 to 249) that contains two DE(D)XRH motifs exhibited a high degree of conservation $(74 \%)$. Two DE(D)XRH motifs with an approximately 100 amino acid interval have been suggested to be the diiron-oxo cluster binding site (Fox et al., 1993); this cluster is considered to be the catalytic centre of the oxygenases. Therefore, it would be reasonable to assume that amino acids around this conserved region may interact with substrates and may thus be involved in determining the kinetic properties of phenol hydroxylases. A comparison of the deduced amino acid sequence of the phenol hydroxylase of strain E2 with those of the other phenol hydroxylases shown in this paper would facilitate the identification of amino acids that determine the kinetic properties of phenol hydroxylases.

\section{ACKNOWLEDGEMENTS}

We thank Shigeaki Harayama for helpful advice and critical reading of this manuscript. We also thank Ronald $\mathrm{H}$. Olsen for donating bacterial strains and plasmids, Masanori Fujita for donating plasmids and Ikuko Hiramatsu for technical assistance.

\section{REFERENCES}

Abril, M. A., Buck, M. \& Ramos, J. L. (1991). Activation of the Pseudomonas TOL plasmid upper pathway operon: identification of binding sites for the positive regulator XylR and for integration host factor protein. J Biol Chem 266, 15832-15838.

Chakrabarty, A. M., Mylroie, J. R., Friello, D. A. \& Vacca, J. G. (1975). Transformation of Pseudomonas putida and Escherichia coli with plasmid-linked drug-resistance factor DNA. Proc Natl Acad Sci USA 72, 3647-3651.

Dixon, R. (1986). The $x y l A B C$ promoter from Pseudomonas putida TOL plasmid is activated by nitrogen regulatory genes in Escherichia coli. Mol Gen Genet 203, 129-136.

Ehrt, S., Schirmer, F. \& Hillen, W. (1995). Genetic organization, nucleotide sequence and regulation of expression of genes encoding phenol hydroxylase and catechol 1,2-dioxygenase in Acinetobacter calcoaceticus NCIB8250. Mol Microbiol 18, 13-20.

Folsom, B. R., Chapman, P. J. \& Pritchard, P. H. (1990). Phenol and trichloroethylene degradation by Pseudomonas cepacia G4: kinetics and interactions between substrates. Appl Environ Microbiol 56, 1279-1285. 
Fox, B. G., Shanklin, J., Somerville, C. \& Munck, E. (1993). Stearylacyl carrier protein $\Delta^{9}$ desaturase from Ricinus communis is a diiron-oxo protein. Proc Natl Acad Sci USA 90, 2486-2490.

Friedman, D. I. (1988). Integration host factor: a protein for all reasons. Cell 55, 545-554.

Fujita, M., Ike, M., Hioki, J., Kataoka, K. \& Takeo, M. (1995). Trichloroethylene degradation by genetically engineered bacteria carrying cloned phenol catabolic genes. J Ferment Bioeng 79, 100-106.

Hashimoto, S., Iwahori, K. \& Iwagami, A. (1992). Phenoldegrading activity of Acinetobacter calcoaceticus AH strain. Hakkokogaku 70, 267-271.

Herrmann, H., Muller, C., Schmidt, I., Mahnke, J., Petruschka, L. \& Hahnke, K. (1995). Localization and organization of phenol degradation genes of Pseudomonas putida strain H. Mol Gen Genet 247, 240-246.

Holloway, B. W., Krishnapillai, V. \& Morgan, A. F. (1979). Chromosomal genetics of Pseudomonas. Microbiol Rev 43, 73-102.

Holtel, A., Timmis, K. N. \& Ramos, J. L. (1992). Upstream binding sequences of the XylR activator protein and integration host factor in the XylS gene promoter region of the Pseudomonas TOL plasmid. Nucleic Acids Res 20, 1755-1762.

Kukor, J. J. \& Olsen, R. H. (1990). Molecular cloning, characterization, and regulation of a Pseudomonas pickettii PKO1 gene encoding phenol hydroxylase and expression of the gene in Pseudomonas aeruginosa PAO1c. J Bacteriol 172, 4624-4630.

Kustu, S., Santero, E., Keener, J., Popham, D. \& Weiss, D. (1989). Expression of $\sigma^{54}$ (ntrA)-dependent genes is probably united by a common mechanism. Microbiol Rev 53, 367-376.

Machado, R. J. \& Grady, L., Jr (1989). Dual substrate removal by an axenic bacterial culture. Biotechnol Bioeng 33, 327-337.

Marmur, J. (1961). A procedure for the isolation of deoxyribonucleic acid from microorganisms. J Mol Biol 3, 208-218.

Ng, L. C., Shingler, V., Sze, C. C. \& Poh, C. L. (1994). Cloning and sequencing of the first eight genes of the chromosomally encoded (methyl) phenol degradation pathway from Pseudomonas putida P35X. Gene 151, 29-36.

Nordlund, I., Powlowski, J. \& Shingler, V. (1990). Complete nucleotide sequence and polypeptide analysis of multicomponent phenol hydroxylase from Pseudomonas sp. strain CF600. J Bacteriol 172, 6826-6833.

Nurk, A., Kasak, L. \& Kivisaar, M. (1991). Sequence of the gene (pheA) encoding phenol monooxygenase from Pseudomonas sp. EST1001: expression in Escherichia coli and Pseudomonas putida. Gene 102, 13-18.

Olsen, R. H., DeBusscher, G. \& McCombie, J. M. (1982). Development of broad-host-range vectors and gene banks: self-cloning of the Pseudomonas aeruginosa PAO chromosome. J Bacteriol 150, $60-69$.
Pearson, W. R. (1990). Rapid and sensitive sequence comparison with FASTP and FASTA. Methods Enzymol 183, 63-98.

Pearson, W. R. \& Lipman, D. J. (1988). Improved tools for biological sequence analysis. Proc Natl Acad Sci USA 85, 2444-2448.

Polissi, A. \& Harayama, S. (1993). In vivo reactivation of catechol 2,3-dioxygenase mediated by a chloroplast-type ferredoxin: a bacterial strategy to expand the substrate specificity of the aromatic degradative pathway. EMBO J 12, 3339-3347.

Powlowski, J. \& Shingler, V. (1990). In vitro analysis of polypeptide requirements of multicomponent phenol hydroxylase from Pseudomonas sp. strain CF600. J Bacteriol 172, 6834-6840.

Sambrook, J., Fritsch, E. F. \& Maniatis, T. (1989). Molecular Cloning: a Laboratory Manual, 2nd edn. Cold Spring Harbor, NY: Cold Spring Harbor Laboratory.

Shine, J. \& Dalgarno, L. (1975). Determination of cistron specificity in bacterial ribosomes. Nature 254, 34-38.

Shingler, V. (1996). Molecular and regulatory check points in phenol degradation by Pseudomonas sp. CF600. In Molecular Biology of Pseudomonads, pp. 153-164. Edited by T. Nakazawa, K. Furukawa, D. Haas \& S. Silveri. Washington, DC: American Society for Microbiology.

Shingler, V., Bartilson, M. \& Moore, T. (1993). Cloning and nucleotide sequencing of the gene encoding the positive regulator (DmpR) of the phenol catabolic pathway encoded by pVI150 and identification of DmpR as a member of the NtrC family of transcriptional activators. J Bacteriol 175, 1596-1604.

Staskawicz, B., Dahlbeck, D., Keen, N. \& Napoli, C. (1987). Molecular characterization of cloned avirulence genes from race 0 and race 1 of Pseudomonas syringae pv. glycinea. J Bacteriol 169, 5789-5794.

Takeo, M., Maeda, Y., Okada, H., Miyama, K., Mori, K., Ike, M. \& Fujita, M. (1995). Molecular cloning and sequencing of phenol hydroxylase gene from Pseudomonas putida BH. J Ferment Bioeng 79, 485-488.

Thompson, J. D., Higgins, D. G. \& Gibson, T. J. (1994). CLUSTAL w : improving the sensitivity of progressive multiple sequence alignment through sequence weighting, positions-specific gap penalties and weight matrix choice. Nucleic Acids Res 22, 4673-4680.

Watanabe, K. \& Hino, S. (1996). Identification of a functionally important population in phenol-digesting activated sludge with antisera raised against isolated bacterial strains. Appl Environ Microbiol 62, 3901-3904.

Watanabe, K., Hino, S., Onodera, K., Kajie, S. \& Takahashi, N. (1996). Diversity in kinetics of bacterial phenol-oxygenating activity. J Ferment Bioeng 81, 562-565.

Received 28 January 1998; revised 10 March 1998; accepted 12 March 1998. 